\title{
New species of Eiphosoma Cresson 1865 (Hymenoptera, Ichneumonidae, Cremastinae) from Brazil
}

\author{
Onody, HC. *, Melo, IF., Penteado-Dias, AM. and Dias-Filho, MM. \\ Departamento de Ecologia e Biologia Evolutiva, Universidade Federal de São Carlos - UFSCar, \\ CP 676, CEP 13565-905, São Carlos, SP, Brazil \\ *e-mail: helenaonody@yahoo.com.br \\ Received March 11, 2009 - Accepted March 18, 2009 - Distributed November 30, 2009
}

(With 6 figures)

\begin{abstract}
Eiphosoma Cresson 1865 is a very species rich New World genus of Cremastinae (Ichneumonidae) comprising about 51 described neotropical species, 17 of which occur in Brazil (Costa Lima, 1953; Gauld, 2000; Yu et al., 2005; Triana and Ravelo, 2007). The tropical American species of Eiphosoma Cresson 1865 belong to nine distinct species group characterized by Gauld (2000).

It is an easily distinctive and very common genus that occurs in open and degraded habitats, being an important natural enemy of agricultural lepidopterous pests (Triana and Ravelo, 2007).

Amongst the material collected from organic agroecosystems in southeast Brazil, five Eiphosoma Cresson 1865 specimens were identified as a new species. Other species of Ichneumonidae has been studied with material collected in several Brazilian ecosystems (Onody and Penteado-Dias, 2006; Onody et al., 2009; Loffredo and Penteado-Dias, 2008 a,b). The terminology in this study follows Gauld (2000) and all specimens are deposited in the DCBU collection (Department of Ecology and Evolutionary Biology, UFSCar, São Carlos, SP, Brazil).
\end{abstract}

\section{Eiphosoma oyafusoi sp. nov. (Figures 1-5)}

\subsection{Description}

Female (Figure 1): Fore wing length 4.2-5.2 mm. Mandible quite stout, evenly tapered towards distal end, with upper tooth about same length the lower, but slight stouter; clypeus, in profile, moderately convex; malar space 0.5-0.7 times as long as basal mandibular width, posterior ocellus separated from eye about its own maximum diameter, basal three flagellomeres with short pubescence. Pronotum with weak epomia, mesoscutum punctate, scutellum centrally smooth and polished; lower part of mesopleuron with fine setiferous punctures, subalar prominence striate; sternaulus strongly impressed only anteriorly; upper end of epcnemial carina reaching front end of pleuron about 0.5 way up of pronotum; metapleuron moderately convex, finely punctate; pleural carina quite strong and complete; submetapleural carina moderately raised anteriorlly. Propodeum striate except for the area before the anterior transverse carina that is polished with few punctures, anterior transverse strongly angled forwards, posterior transverse carina present, but weak. Hind leg with trochantellus, in dorsal view, about
0.8 times as long as trochanter, hind tarsal claw short, pectinate basally. Fore wing (Figure 5) with 3 rs-m absent, with $1 \mathrm{~m}-\mathrm{cu}$ joining to $2 \mathrm{rs}-\mathrm{m}$ closer to RS than to $\mathrm{M}$; distal abscissa of M complete; cu-a opposite to base of RS and M. Metasoma with tergite I posteriorlly weakly swollen. Ovipositor slightly bowed 1.3-1.4 times as long as hind tibia, its apex straight, and ovipositor sheath closely hirsute.

Head yellow with upper part of occiput, frons centrally, and vertex black, mesosoma (Figure 3) yellow, mesoscutum with three longitudinal black stripes joining with the hind margin; scutellum yellow, posteriorlly black marked; mesopleuron with a diagonal black band; sternauli black marked; propodeum (Figure 4) with black marks anteriorly and centrally; metasoma with tergite I centrally pale, proximally and distally blackish, the other tergites are yellowish brown, dorsally blackish. Anterior two pairs of legs yellow; hind legs with coxa yellowish, with black marks, on inner and outer sides, trochanters blackish apically yellowish; trochantellus dorsally blackwish, lateroventrally yellowish, femur basally and subapically black, yellowish brown centrally and apically, hind tibia black, centrally yellowish brown, tarsus black; fore wing hyaline, apically weakly infumate; pterostigma brown.

Male (Figure 2): similar to female in structure and colour, aedeagus with a few short bristles present laterally subapically, and with a tuft of longer bristles present ventrally at about midlength hairs on distal margin of claspers moderately long.

Etymology: The species name refers to the holotype locality.

Remarks: Eiphosoma oyafusoi belongs to a complex of species within the E. nigrovittatum species-group characterized by absence of the areolet and black-marked yellow hind coxa. Within this complex it most closely resembles E. urgulium Gauld 2000, differing from this species in having the propodeum striate with a median black longitudinal mark that anteriorly does not reach the transverse black band and the anterior transverse carina complete though with median angulation very strong.

Biological notes: One exemplar was obtained from the larvae of Diaphania hyalinata Linnaeus (Lepidoptera, Pyralidae) collected in Eruca sativa Miller organic cultivars. The Figure 6 illustrate the cocoon where emerged a female specimen. 

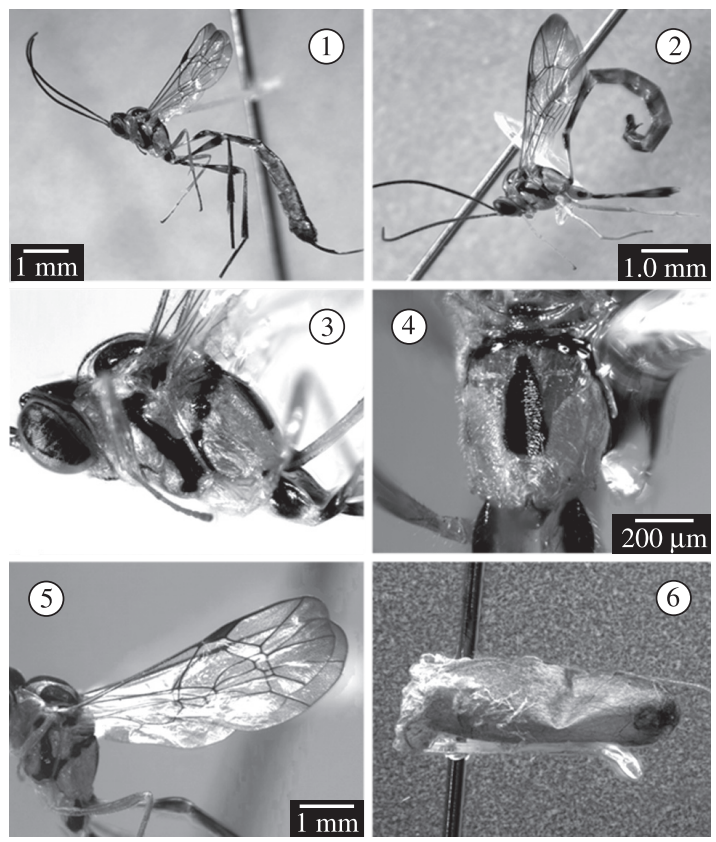

Figures 1-6. Eiphosoma oyafusoi sp. nov., 1) holotype $q$ (habitus); 2) paratype $\hat{\sigma}$ (habitus); 3) mesosoma (holotype, lateral aspect); 4) propodeum (holotype); 5) wings (holotype); and 6) cocoon.

\subsection{Material examined}

Holotype + . Brasil. São Paulo, Araraquara, Horta Oyafuso, 10/IV/2006, Eruca sativa cultivars, on Diaphania hyalinata larva, Onody, H. C. col. Paratypes: $\left(1 \delta^{\lambda}\right)$ 06/X/2006, Malaise trap, same locality of holotype; (1) São Carlos, Horta da Prefeitura de São Carlos, 11/IX/2006, Malaise trap; (2ð) São Carlos, Horta da Prefeitura de São Carlos, 11/X/2006, Malaise trap.
Acknowledgements - The authors are grateful to FAPESP (Fundação de Amparo à Ciência do Estado de São Paulo) and to $\mathrm{CNPq}$ (Conselho Nacional de Desenvolvimento Científico e Tecnológico) for financial support; to Marcelo Oyafuso and the Prefeitura de São Carlos, SP, Brazil for allowing the collections on their properties.

\section{References}

COSTA-LIMA, A. Espécies de Eiphosoma Cresson (Hymenoptera, Ichneumonidae, Ophioninae). Arquivos do Museu Naional, 1953, vol. 42, p. 175-189.

GAULD, I. The Ichneumonidae of Costa Rica, 3. Memoirs of the American Entomological Institute, 2000, vol. 63, p. 1-453.

LOFFREDO, APS. and DIAS, AMPM. First record of Schizopyga gravenhorst (Hymenoptera, Ichneumonidae, Pimplinae) from Brazil and a description of a new species. Revista Brasileira de Biologia = Brazilian Journal of Biology, 2008, vol. 68, no. 2, p. 456-458.

LOFFREDO, APS. and DIAS, AMPM. First record of Ticapimpla vilmae Gaud 1991 (Hymenoptera, Ichneumonidae, Pimplinae) from Brazil. Revista Brasileira de Biologia = Brazilian Journal of Biology, 2008, vol. 68, no. 4, p. 911.

ONODY, HC. and DIAS, AMPM. Aiura, a new genus of Campopleginae (Hymenoptera; Ichneumonidae) from Brazil. Revista Brasileira de Biologia = Brazilian Journal of Biology, 2006, vol. 66, no. 2B, p. 755-758.

ONODY, HC., LOFFREDO, APS. and DIAS, AMPM. The Brachycyrtus Kriechbaumer species (Hymenoptera, Ichneumonidae, Brachycyrtinae) from Brazil. Revista Brasileira de Biologia = Brazilian Journal of Biology, vol. 69, no 3, p. 631-637.

TRIANA, JLF. and RAVELO, HG. A taxonomic review of Cuban Eiphosoma Cresson (Hymenoptera, Ichneumonidae), with biogeographical notes. Zootaxa, 2007, vol. 1655, p. 49-61.

YU, DS., ACHTERBERG, C. and HORSTMANN, K. World Ichneumonoidea 2004: taxonomy, biology and distribution. Vancouver: Taxapad, 2005. (Versão em CD-ROM). 